\title{
Evaluation of a Rhodomyrtus tomentosa ethanolic extract for its therapeutic potential on Staphylococcus aureus infections using in vitro and in vivo models of mastitis
}

\author{
Auemphon Mordmuang ${ }^{1,3}$, Eric Brouillette ${ }^{2}$, Supayang Piyawan Voravuthikunchai ${ }^{{ }^{*}}$ and François Malouin ${ }^{2^{*}}$ (D)
}

\begin{abstract}
An ethanolic extract from Rhodomyrtus tomentosa leaves (RTL) was studied as a natural alternative to control Staphylococcus aureus, which is an important pathogen responsible for bovine mastitis. The minimal inhibitory concentrations (MICS) of the RTL extract and of rhodomyrtone, a pure compound isolated from the plant, were determined by a microdilution method. Rhodomyrtone and the RTL extract exhibited antibacterial activity against $S$. aureus, including its persistent phenotype (SCV: small-colony variant) and a biofilm hyperproducer strain, with MICs of 0.25-0.5 and 8-16 $\mu \mathrm{g} / \mathrm{mL}$, respectively. Time-kill kinetics showed a strong bactericidal activity for both the RTL extract- and rhodomyrtone-treated bacteria at $2 \times$ MIC as early as $4 \mathrm{~h}$ post-exposure. An additive effect of the extract at $0.5 \times$ MIC was observed in a combination with oxytetracycline or pirlimycin against $S$. aureus by showing a 64- to 128 -fold reduction in antibiotic MICs. Moreover, the RTL extract significantly decreased the number of intracellular SCVs inside bovine mammary epithelial cells. However, the extract or its combination with pirlimycin only slightly improved the activity of pirlimycin against the bacterial colonization of mouse mammary glands. In vitro MICs determined in the presence of casein indicated that the limited activity of the RTL extract in the murine model of mastitis could be linked to neutralization of active components by milk proteins. While the RTL extract showed interesting antibacterial properties in vitro, to be considered as an alternative to antibiotics in dairy farms, formulation studies are needed to cope with the observed reduction of activity in vivo.
\end{abstract}

\section{Introduction}

Bovine mastitis caused by Staphylococcus aureus is an important problem in the dairy industry worldwide. The bacterium is associated with subclinical and clinical bovine mastitis, that can spread contagiously to other animals in the herd [1-3]. S. aureus produces many

\footnotetext{
*Correspondence: supayang.v@psu.ac.th;

francois.malouin@usherbrooke.ca

${ }^{1}$ Department of Microbiology and Excellence Research Laboratory on Natural Products, Faculty of Science and Natural Product Research Center of Excellence, Prince of Songkla University, Hat Yai, Songkhla 90112, Thailand

${ }^{2}$ Centre d'Étude et de Valorisation de la Diversité Microbienne (CEVDM), Département de biologie, Faculté des sciences, Université de Sherbrooke, Sherbrooke, QC J1K 2R1, Canada

Full list of author information is available at the end of the article
}

toxins including extracellular hydrolytic enzymes that can impair host defenses and damage mammalian cells and tissues but one of the crucial functional mechanisms of $S$. aureus virulence is its ability to invade, persist and replicate inside host cells $[4,5]$.

Staphylococcus aureus strain Newbould, a prototypic strain isolated from a case of clinical bovine mastitis and its laboratory-derived hemB-deleted mutant strain, a small colony variant (SCV), have been extensively studied for their phenotype and role in persistent infections [6, 7]. The ability of SCVs to persist in phagocytic cells or in nonprofessional phagocytes such as fibroblasts, endothelial cells, and epithelial cells has been established [8-10]. Internalization of bacteria into host cells can facilitate evasion from the host immune system and is a phenomenon that is associated with 
the chronic or recurrent manifestation of the disease. Switching from the normal to the SCV phenotype and vice versa is believed to be part of the natural infection process for $S$. aureus [11]. In addition, clinical SCVs have been frequently isolated following antibiotic pressure $[12,13]$. SCVs have been detected in persistent bovine mastitis [14] and a therapeutic solution for $S$. aureus bovine mastitis needs to be successful against the SCV phenotype.

Antibacterial therapies are being challenged by the widespread development of bacterial resistance. Bacterial strains designated as methicillin-resistant $S$. aureus (MRSA) have been isolated from bovine milk [15]. In addition to the occurrence of antibiotic resistant strains, which may be spread from cow to cow by contaminated equipment or in the community by farm workers, treatment of intramammary infections using antibiotics increases consumer concerns about foodrelated health risks and problems associated with drug residues in milk. Therefore, attempts of using natural alternatives to antibiotics for treatment of mastitis have been made, in order to minimize the usage of traditional antibiotics or chemical agents in the animal food industry [16]. The reduction of antibiotic use and discovery of alternatives in agri-food sectors where antibiotics are heavily used should directly benefit human health as it may limit and prevent the development of antibiotic resistance.

Rhodomyrtus tomentosa is a medicinal plant belonging to the Myrtaceae family and an ethanolic leaf extract of the plant was previously shown to have an antibacterial activity against Gram-positive bacteria including $S$. aureus, coagulase-negative staphyloccocci and Streptococcus spp., that are widely found as causative agents of bovine mastitis [17]. In addition, rhodomyrtone, a pure compound isolated from this plant, has demonstrated a strong inhibitory effect against $S$. aureus similar to that obtained with vancomycin, an important anti-S. aureus drug in human medicine [18]. Recently, we have reported that a $R$. tomentosa ethanolic leaf (RTL) extract affected $S$. aureus cell surface properties by increasing its hydrophobicity and consequently disturbed bacterial adhesion and invasion into host cells in an ex vivo bovine udder epidermal tissue model [19].

The use of a plant extract that is easy to produce could facilitate its introduction as a novel natural alternative to antibiotics. In the present study, the aims were to determine the effect of the RTL extract on the ability of $S$. aureus to invade bovine mammary epithelial cells, to specifically include $S$. aureus SCVs among the studied bacterial targets, and to investigate any possible synergistic effects the RTL extract could have with traditional antibiotics, in order to improve their therapeutic efficacy or to reduce the amounts needed. A mastitis-relevant mouse S. aureus intramammary infection model was used to evaluate in vivo efficacy.

\section{Materials and methods \\ Bacterial strains and growth conditions}

Staphylococcus aureus strains used in this study included Newbould (ATCC 29740) and its laboratoryderived isogenic small colony variant (SCVs) counterpart $(\Delta h e m B)$ that was described before [6]. Also included was strain SHY97-3906 that was isolated from a case of clinical bovine mastitis [20]. Other isolates were selected from the Mastitis Pathogen Culture Collection (MPCC) belonging to the Canadian bovine mastitis and milk quality research network (CBMQRN, St-Hyacinthe, QC, Canada), as described in detail in Reyher et al. [2]. These isolates included one bovine methicillin-resistant $S$. aureus (MRSA strain 1158, spa type t451, barcode 1081-2464), one biofilm hyperproducer (strain 2117, spa type t13401, barcode 10705001) evidenced in a previous study [21], as well as strains 2236 (spa type t257, barcode 2090-2582), and 2290 (spa type t529, barcode 2110-3742). Also from the collection were two coagulase-negative strains such as S. simulans 3100-0949 and S. chromogenes 3140-3115 that were used for antibacterial activity testing. The bacterial strains were maintained on tryptic soy agar or broth (TSA or TSB) as well as on mannitol salt agar (MSA), all from Becton-Dickinson (USA), and grown at $35^{\circ} \mathrm{C}$ for $18-24 \mathrm{~h}$.

\section{Preparation of $R$. tomentosa leaf (RTL) extract and rhodomyrtone}

The leaves of Rhodomyrtus tomentosa (Aiton) Hassk. were collected from the Singha Nakhon district, in the Songkhla province (Thailand) by Dr. Asadhawut Hiranrat (Department of Organic Chemistry, Faculty of Science, Prince of Songkla University). The voucher specimen (A. Hiranrat 001) was identified by J. Wei and has been deposited in the herbarium of Department of Biology, Faculty of Science, Prince of Songkla University, Thailand [22]. R. tomentosa leaves were dried in an oven at $60{ }^{\circ} \mathrm{C}$ for $48 \mathrm{~h}$ and ground in an electric blender. Dried leaf powder was extracted with $95 \%$ ethanol at room temperature and kept in the dark for 1 week. The extract was evaporated for 48 to $72 \mathrm{~h}$ by a rotary evaporator (BUCHI Rotavapor R-114, Büchai Labortechnik AG, Flawil, Switzerland) until it was completely dry (visual inspection). The extract was then dissolved in dimethyl sulfoxide (DMSO, Sigma-Aldrich Inc., Oakville, Canada). Pure 
rhodomyrtone (Sigma-Aldrich Inc.) was also dissolved in DMSO and kept at $-20^{\circ} \mathrm{C}$ until used.

\section{Determination of the minimum inhibitory concentration (MIC) and minimum bactericidal concentration (MBC)}

The minimum inhibitory concentrations (MICs) of the RTL extract, rhodomyrtone and other antibiotics were determined by a broth microdilution method according to the recommendations from the Clinical Laboratory Standards Institute (CLSI) for antimicrobial susceptibility testing [23]. The antibacterial agents, prepared in cationadjusted Mueller-Hinton broth (CAMHB, Becton-Dickinson, Mississauga, Canada) to a final concentration of $256 \mu \mathrm{g} / \mathrm{mL}$ (highest concentration having $\leq 0.5 \%$ DMSO), were separately added and further diluted by twofold serial dilutions in 96-well plates. An equal volume of a bacterial suspension $\left(\sim 1 \times 10^{6}\right.$ colony-forming units $(\mathrm{CFU}) / \mathrm{mL}$ ) was added to each well containing the antibacterial agents and incubated at $35{ }^{\circ} \mathrm{C}$ for $18-24 \mathrm{~h}$. In all assays, sterility and bacterial growth controls were included. Vancomycin (Sigma-Aldrich Inc.) and pirlimycin hydrochloride (Pirsue ${ }^{\circledR}$, Zoetis Canada Inc., Kirkland, Canada) were included as reference drugs and for quality controls. The MIC was defined as the lowest concentration of drug yielding no visible growth. The minimum bactericidal concentration (MBC) was determined subsequent to the MIC assay. A $10-\mu \mathrm{L}$ aliquot from the visually clear wells containing the MIC value and higher concentrations were spread onto TSA plates. The agar plates were incubated at $35{ }^{\circ} \mathrm{C}$ for $18 \mathrm{~h}$. The $\mathrm{MBC}$ was defined as the concentration killing $99.9 \%$ of the initial inoculum. In some specified experiments, $5 \%$ casein (SigmaAldrich Inc.) was added to CAMHB to mimic the milk environment.

\section{Checkerboard assay and determination of the fractional inhibitory concentration (FIC) index}

A two-dimensional broth microdilution checkerboard assay was performed to determine the MICs of the RTL extract or rhodomyrtone in combination with 10 antibiotics, including ampicillin, amoxicillin, penicillin, oxacillin, ceftiofur, ciprofloxacin, gentamicin, kanamycin, pirlimycin, and oxytetracycline against $S$. aureus Newbould. The antibiotics were serially diluted in the $y$-axis and the extract or rhodomyrtone in the $x$-axis. An equal volume of a bacterial suspension $\left(\sim 1 \times 10^{6} \mathrm{CFU} / \mathrm{mL}\right)$ was added to each well containing the antibacterial agents and incubated at $35{ }^{\circ} \mathrm{C}$ for $18-24 \mathrm{~h}$. In all assays, sterility and bacterial growth controls were included. The MIC was defined as the lowest concentration of drug (alone or in combination) yielding no visible growth. The antibacterial effect of each combination was determined by means of the FIC according to the following equation [24]:

$$
\begin{aligned}
\mathrm{FIC}_{\mathrm{A}} & =M I C_{\text {combination }} / M I C_{A}, \\
\mathrm{FIC}_{\mathrm{B}} & =M I C_{\text {combination }} / M I C_{B}, \\
\sum \mathrm{FIC} & =\mathrm{FIC}_{\mathrm{A}}+\mathrm{FIC}_{\mathrm{B}}
\end{aligned}
$$

The FIC index ( $\mathrm{FFIC}$ ) was interpreted as follows: $\sum$ FIC $\leq 0.5$, synergism; $>0.5-1$, additivity; $>1-4$, indifference; $\geq 4$, antagonism.

\section{Kill kinetics}

The bactericidal activity of the RTL extract and rhodomyrtone against $S$. aureus was assessed by time-kill experiments. S. aureus Newbould and its isogenic $\Delta$ hemB mutant were used as representative strains for the wildtype and SCV phenotype, respectively. The bacterial inoculum $\left(\sim 1 \times 10^{6} \mathrm{CFU} / \mathrm{mL}\right)$, as evaluated by turbidity using McFarland standards and confirmed by plating on agar for CFU counts, was grown with CAMHB supplemented with the plant ethanolic extract or rhodomyrtone at concentrations of $0.5 \times, 1 \times, 2 \times$, and $4 \times$ their respective MIC value. The bacterial cultures were incubated at $35^{\circ} \mathrm{C}$ with shaking and their growth was monitored over $24 \mathrm{~h}$. Samples were collected at various time intervals followed by tenfold serial dilutions. A $10 \mu \mathrm{L}$ aliquot was spread onto TSA plates for determination of the CFU. The bacterial growth kinetics was analyzed by plotting $\log 10 \mathrm{CFU} / \mathrm{mL}$ versus time.

\section{Cell culture}

Bovine mammary gland epithelial cells (MAC-T) were cultured in growth medium composed of Dulbecco's Modified Eagle's Medium (DMEM, Wisent Inc., SaintJean-Baptiste, Canada) supplemented with $10 \%$ inactivated fetal bovine serum (FBS, Wisent Inc.), 1\% sodium pyruvate, $10 \mu \mathrm{g} / \mathrm{mL}$ insulin, $5 \mu \mathrm{g} / \mathrm{mL}$ hydrocortisone, $100 \mathrm{units} / \mathrm{mL}$ penicillin, $100 \mu \mathrm{g} / \mathrm{mL}$ streptomycin, and $0.025 \mu \mathrm{g} / \mathrm{mL}$ of fungizone. The cells were passaged twice a week up to ten passages after being thawed from the stock culture and incubated in $5 \% \mathrm{CO}_{2}$ at $37{ }^{\circ} \mathrm{C}$. A confluent monolayer of the cell culture was treated with a $0.25 \%$ trypsin solution (Wisent Inc.) for 3-5 min and neutralized by adding DMEM supplemented with $10 \%$ FBS. Single cells were collected from the suspension after centrifugation using an Allegra ${ }^{\mathrm{TM}}$ 6R centrifuge (Beckman Coulter Canada LP, Mississauga, Canada) at $250 \mathrm{~g}, 25^{\circ} \mathrm{C}$, for $10 \mathrm{~min}$. For specified 
experiments, aliquots of $250 \mu \mathrm{L}$ of MAC-T cells were seeded into 24-well culture plates and incubated in the growth medium at $37{ }^{\circ} \mathrm{C}$ in a humidified incubator with $5 \% \mathrm{CO}_{2}$, until the desired confluence was reached.

\section{Cytotoxicity test}

The cytotoxicity of the RTL extract, rhodomyrtone or pirlimycin for MAC-T cells was quantified using a lactate dehydrogenase (LDH) assay according to the manufacturer's instructions (LDH Cytotoxicity detection kit, Roche Diagnostics GmbH, Mannheim, Germany). The day before the experiment, the suspension of MAC-T cells was adjusted to $2 \times 10^{5}$ cells $/ \mathrm{mL}$ in the growth medium and $250 \mu \mathrm{L}$ of the cell suspension were added into 48 -well tissue culture plates. The plates were incubated at $37{ }^{\circ} \mathrm{C}$ for $24 \mathrm{~h}$ in a humidified incubator with $5 \% \mathrm{CO}_{2}$ to obtain a confluent monolayer $\left(\sim 1 \times 10^{5}\right.$ cells/well). The cell monolayer was washed twice with DMEM and the growth medium was replaced with the assay medium (DMEM supplemented with $1 \%$ FBS without antibiotics) containing different concentrations of the tested agents. A $1 \%$ triton X-100 solution (Sigma-Aldrich Inc.) and the assay medium itself were used as a high cytotoxicity control and the low cytotoxicity control, respectively. Cell-free supernatants were separately collected after treating for 8-12 h. An aliquot of $100 \mu \mathrm{L}$ from each tested and control well were transferred to a 96-well plate, followed by adding $100 \mu \mathrm{L}$ of the LDH reaction mixture. The LDH reaction in each sample was measured by the optical density (OD) at $490 \mathrm{~nm} / 660 \mathrm{~nm}$ using a spectrophotometric plate reader. The experiments were performed in triplicate. Percentage of cytotoxicity of antibacterial compounds were determined and calculated according to the formula provided by the manufacturer, as follows:

$$
\begin{aligned}
\text { Cytotoxicity }(\%)= & {[(\text { OD of the tested cell mixture }} \\
& - \text { OD of the compound alone }) \\
& - \text { OD low control }] / \\
& {[(\text { OD high control }- \text { OD low control })] } \\
& \times 100
\end{aligned}
$$

\section{Bacterial invasion assay}

MAC-T cells were adjusted to $5 \times 10^{4}$ cells $/ \mathrm{mL}$ with growth medium and $500 \mu \mathrm{L}$ of the cell suspension was added into 24-well tissue culture plates. The plates were incubated at $37{ }^{\circ} \mathrm{C}$ for $48 \mathrm{~h}$ to obtain a $>80 \%$ confluent monolayer $\left(\sim 1.5 \times 10^{5}\right.$ cells/well $)$. The cell monolayer was washed twice with DMEM, shielded with $500 \mu \mathrm{L}$ of invasion medium (DMEM supplemented with 1\% FBS without antibiotics), and re-incubated for $4 \mathrm{~h}$. The cell monolayers were then washed with DMEM and the cell culture medium was replaced with $500 \mu \mathrm{L}$ of the freshly prepared bacterial suspension at a multiplicity of infection (MOI) of 10 or 100 . Bacterial cell suspensions were prepared by adding an overnight culture of $S$. aureus into fresh TSB (1:20) containing $1 / 2 \times$ MIC of the RTL extract or rhodomyrtone and incubated at $35{ }^{\circ} \mathrm{C}$ for $2 \mathrm{~h}$. Vancomycin (also at $1 / 2 \times \mathrm{MIC}$ ) was used as the reference drug. All cultures contained 0.25\% DMSO. These pretreated bacterial cells were then washed twice with cold sterile PBS and the bacterial suspension was adjusted to $3 \times 10^{6} \mathrm{CFU} / \mathrm{mL}$ in the invasion medium. After bacteria were added, each well was filled to $1 \mathrm{~mL}$ by adding $500 \mu \mathrm{L}$ of the test antibiotics at half its MIC. The plates were incubated at $37{ }^{\circ} \mathrm{C}$ for $3 \mathrm{~h}$. Unattached and extracellular bacteria were then removed from the monolayers by washing twice with DMEM and possible residual extracellular bacteria were eliminated by adding $700 \mu \mathrm{L}$ of $2 \mu \mathrm{g} / \mathrm{mL}$ lysostaphin (Sigma-Aldrich). The culture was further incubated for $30 \mathrm{~min}$, therefore, the total incubation period was subsequently $3.5 \mathrm{~h}$. After incubation, the cell monolayers were washed twice with D-PBS (Wisent Inc, Canada), trypsinized with $100 \mu \mathrm{L}$ of trypsin solution for $10 \mathrm{~min}$, and lysed with $900 \mu \mathrm{L}$ of sterile distilled water for $5 \mathrm{~min}$. The cell lysates were mixed thoroughly to release intracellular bacteria. The number of CFU was determined by the standard colony counting technique on TSA. Data are presented as the percentage of bacteria that were internalized relative to the initial bacterial suspension exposed to MAC-T cells.

\section{Efficacy in a mouse mastitis model}

An in vivo study was carried out using a mouse mastitis model according to the method described previously [25] with few modifications. Briefly, CD-1 lactating mice (Charles River, St-Constant, Canada) were used 12 to 14 days after off spring birth. The pups were removed $1 \mathrm{~h}$ before challenged with $100 \mu \mathrm{L}$ of $S$. aureus strain 2117 or Newbould (200 CFU/gland) via intramammary inoculation in both the L4 (on the left) and R4 (on the right) abdominal mammary glands. Mammary glands were treated (intramammary administration) with the RTL extract ( $300 \mu \mathrm{g}$ per dose, 2 doses to achieve maximal concentration), with pirlimicin ( $1 \mu \mathrm{g}$ per dose) or a combination of both. For the extract, treatment was done at 0 and $4 \mathrm{~h}$ post-infection, whereas pirlimycin was administered at $4 \mathrm{~h}$. PBS was used for the untreated control. The mammary glands were collected and homogenized at $16 \mathrm{~h}$ post-infection. The samples were serially diluted with PBS and plated on TSA and MSA for determination of the number of surviving bacteria. The data represent two independent experiments using several mice and glands in each. The animal experiments were conducted following the guidelines of the Canadian Council on Animal Care and approved by the institutional ethics committee 
on animal experimentation of the Faculté des sciences of Université de Sherbrooke.

\section{Statistical analysis}

In this study, the data were analyzed using the GraphPad Prism Software (v.6.00). Tests used for the analysis of each experiment are specified in the figure legends.

\section{Results}

\section{MIC and MBC of the RTL extract and rhodomyrtone}

The RTL extract showed an antibacterial activity against a series of $S$. aureus and coagulase negative staphylococci (CNS) strains associated with bovine mastitis and had MIC values ranging from 8 to $16 \mu \mathrm{g} / \mathrm{mL}$ (Table 1 ). Noteworthy, the target strains included a S. aureus SCV (Newbould $\Delta h e m B$ ), a bovine MRSA and also a $S$. aureus of the spa type 13401 (strain 2117), producing a significant amount of biofilm [21]. The inhibitory spectrum was similar to that of rhodomyrtone, which however exhibited a stronger antibacterial activity with MIC values that ranged from 0.25 to $0.5 \mu \mathrm{g} / \mathrm{mL}$. The pure compound provided inhibitory activity that was very close to the activity of vancomycin and pirlimycin, which had MIC values ranging from 0.25 to $1 \mu \mathrm{g} / \mathrm{mL}$ (Table 1 ). The MBCs of the RTL extract ranged from 16 to $128 \mu \mathrm{g} / \mathrm{mL}$ (i.e., $2-16$ times the MIC), whereas rhodomyrtone showed MBCs that were 1-4 times its MIC.

\section{Kill kinetics}

The kinetic of bacterial killing by the plant extract and rhodomyrtone was determined by following bacterial counts over $24 \mathrm{~h}$. The agents were used at a sub-inhibitory concentration, at the MIC, and at supra-MICs against $S$. aureus Newbould (Figures $1 \mathrm{~A}$ and $\mathrm{C}$ ) and against its SCV Newbould $\Delta$ hemB (Figures $1 \mathrm{~B}$ and D). The RTL extract at
$1 / 2 \times$ MIC and $1 \times$ MIC inhibited growth of the $S$. aureus by prolonging the bacterial lag phase. A strong bactericidal effect that decreased the number of viable bacterial cells by more than $3 \log 10 \mathrm{CFU} / \mathrm{mL}$ was observed using concentrations above the MIC against both strains within $8 \mathrm{~h}$ (Figures $1 \mathrm{~A}$ and $\mathrm{B}$ ). Treatment with rhodomyrtone showed almost identical kill kinetics than that of the RTL extract at the same multiples of its own MIC, although the concentrations used for the pure compound were much lower (Figures $1 \mathrm{C}$ and D).

\section{Cytotoxicity}

The RTL extract showed a relatively low cytotoxicity on MAC-T cells, which slowly increased in a concentration dependent manner (Table 2). This was similar to that observed with pirlimycin, which is abundantly used for the treatment of bovine mastitis. For the RTL extract, there was $\sim 10-12 \%$ cytotoxicity at the MIC against $S$. aureus strains (i.e., $8-16 \mu \mathrm{g} / \mathrm{mL}$ ). Interestingly, rhodomyrtone was the least cytotoxic at concentrations of $1-32 \mu \mathrm{g} / \mathrm{mL}$ but its cytotoxicity sharply increased to 42 and $82 \%$ at concentrations of 64 and $128 \mu \mathrm{g} / \mathrm{mL}$, respectively (Table 2). Noteworthy, those concentrations of rhodomyrtone represent 128 and 256 times, respectively, the MIC of this pure compound against $S$. aureus (Table 1). Note that, all antibacterial agents tested were diluted and tested in the presence of 3.2\% DMSO (final concentration) and the solution of $3.2 \%$ DMSO that was used as an untreated control showed no toxicity on the MAC-T cell (i.e., no different than the no DMSO control; data not shown).

Inhibition of $S$. aureus internalization into MAC-T cells The number of bacteria internalized into MAC-T cells was first determined. As expected and shown before [7], at a MOI of 10 or 100, internalization of the

Table 1 Minimal inhibitory concentrations (MICs) and minimal bactericidal concentrations (MBCs) of the Rhodomyrtus tomentosa leaves (RTL) extract, rhodomyrtone, and reference antibiotics against staphylococcal strains

\begin{tabular}{|c|c|c|c|c|}
\hline \multirow[t]{2}{*}{ Bacterial strains } & \multicolumn{4}{|c|}{$\mathrm{MIC} / \mathrm{MBC}(\mu \mathrm{g} / \mathrm{mL})$} \\
\hline & RTL extract & Rhodomyrtone & Pirlimycin & Vancomycin \\
\hline Newbould (ATCC 29740) & $16 / 128$ & $0.5 / 0.5$ & $0.5 / 1$ & $0.5 / 1$ \\
\hline Newbould $\triangle$ hemB (SCV) & $8 / 16$ & $0.5 / 1$ & $0.25 / 0.5$ & $0.5 / 1$ \\
\hline S. aureus 1158c (bovine MRSA) & $16 / 64$ & $0.5 / 1$ & $0.5 / 1$ & $0.5 / 1$ \\
\hline S. aureus SHY97-3906 & $8 / 16$ & $0.5 / 1$ & $0.5 / 1$ & $0.5 / 1$ \\
\hline S. aureus 2117 & $16 / 128$ & $0.5 / 1$ & $1 / 2$ & $0.5 / 1$ \\
\hline S. aureus 2236 & $16 / 64$ & $0.5 / 1$ & $1 / 2$ & $0.5 / 1$ \\
\hline S. aureus 2290 & $16 / 32$ & $0.5 / 1$ & $0.5 / 1$ & $0.5 / 0.5$ \\
\hline S. simulans 3100-0949 & $16 / 128$ & $0.5 / 1$ & $0.5 / 1$ & $0.5 / 1$ \\
\hline S. chromogenes 3140-3115 & $16 / 32$ & $0.25 / 1$ & $0.25 / 0.5$ & $0.25 / 0.5$ \\
\hline
\end{tabular}



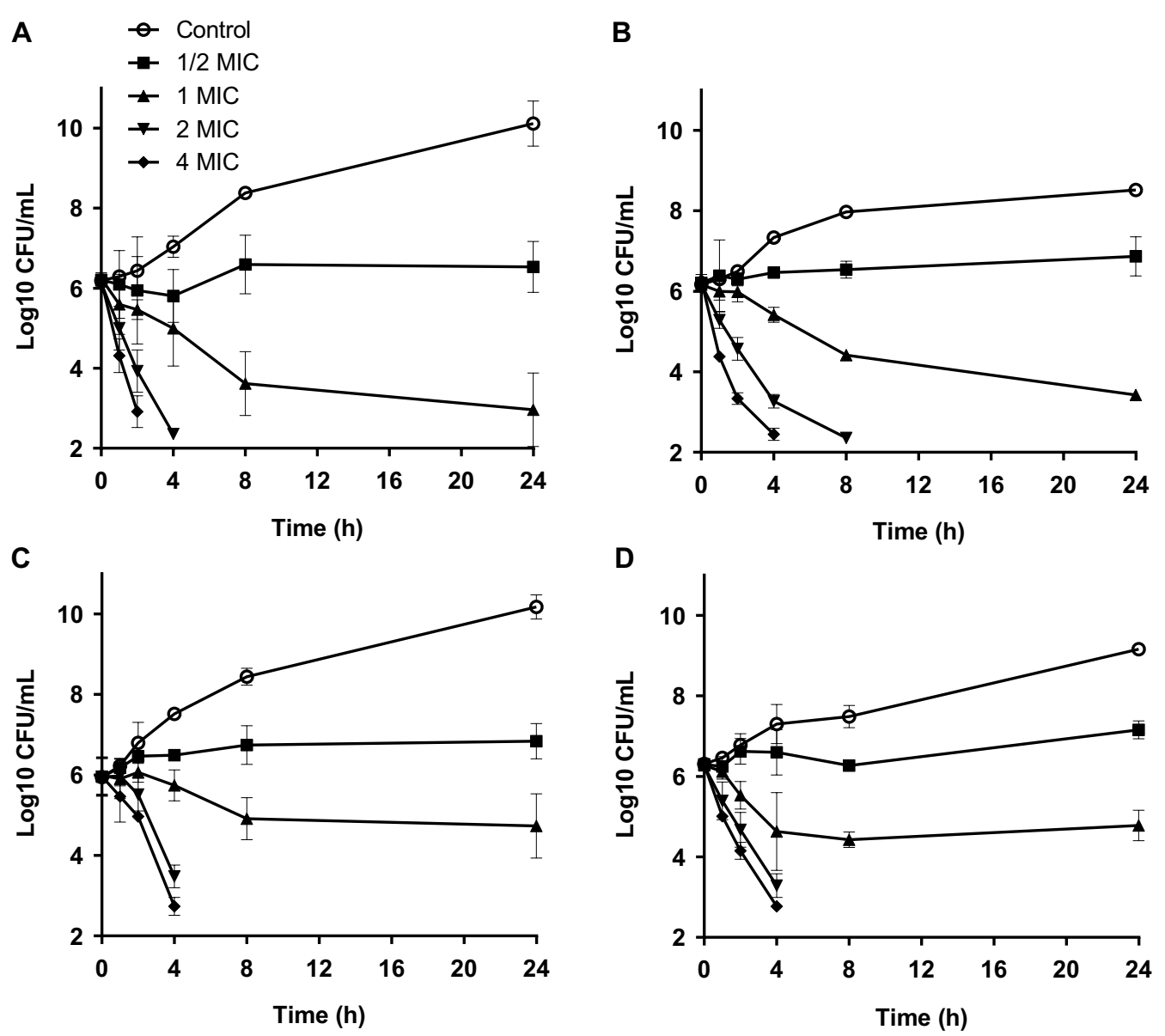

Figure 1 Time-kill kinetics of the Rhodomyrtus tomentosa leaves (RTL) extract (A, B) and rhodomyrtone (C, D) against S. aureus Newbould $(\mathbf{A}, \mathbf{C})$ and its small-colony variant $(\mathbf{S C V}, \mathbf{\Delta h e m B})(\mathbf{B}, \mathbf{D})$. The data are expressed as means of three independent experiments. The detection limit was $100 \mathrm{CFU} / \mathrm{mL}$.

Table 2 Cytotoxicity of the Rhodomyrtus tomentosa leaves (RTL) extract on MAC-T cells as determined by a LDH assay

\begin{tabular}{lccc}
\hline $\begin{array}{l}\text { Concentration } \\
(\boldsymbol{\mu} \mathbf{g} / \mathrm{mL})\end{array}$ & \multicolumn{3}{c}{$\%$ cytotoxicity of antibacterial agents } \\
\cline { 2 - 4 } & $\boldsymbol{R}$. tomentos $\boldsymbol{a}$ extract & Rhodomyrtone & Pirlimycin \\
\hline 1 & $6.2 \pm 1.4$ & $0.2 \pm 0.7$ & $11.5 \pm 1.4$ \\
2 & $6.9 \pm 0.5$ & $0.2 \pm 0.2$ & $14.4 \pm 3.2$ \\
4 & $10.5 \pm 0.6$ & $0.2 \pm 0.2$ & $16.2 \pm 1.3$ \\
8 & $10.9 \pm 1.1$ & $0.3 \pm 0.5$ & $18.9 \pm 0.9$ \\
16 & $12.1 \pm 0.04$ & $0.4 \pm 0.1$ & $20.8 \pm 0.5$ \\
32 & $12.7 \pm 0.1$ & $0.4 \pm 0.3$ & $23.5 \pm 1.9$ \\
64 & $14.5 \pm 1.8$ & $42.2 \pm 0.6$ & $26.6 \pm 3.0$ \\
128 & $16.4 \pm 3.2$ & $81.9 \pm 3.2$ & $28.3 \pm 2.7$ \\
\hline
\end{tabular}

a The \% cytotoxicity was calculated as described in "Materials and methods" section. Values are means of three independent experiments with standard deviations. All compounds were diluted and tested in presence of 3.2\% DMSO (final concentration).
Newbould SCV strain was always significantly greater than that of the prototypical Newbould strain (data not shown). For example, at a MOI of 10, approximately $6 \times 10^{6} \mathrm{CFU} / \mathrm{mL}$ of the SCV strain were recovered from MAC-T cells after $3.5 \mathrm{~h}$ and these conditions were used to evaluate the inhibitory activity of the RTL extract on the internalization process. As shown in Figure 2, the presence of the RTL extract or the pure rhodomyrtone compound (both used at half their MIC) in the extracellular milieu together with the SCV strain, reduced the number of internalized bacteria to approximately 85 and $81 \%$ after $3.5 \mathrm{~h}$, respectively, compared to that found for the untreated control (Figures 2A and B). Vancomycin, also used at half its MIC, showed no significant reduction of the SCV numbers internalized into MAC-T cells compared to the untreated 


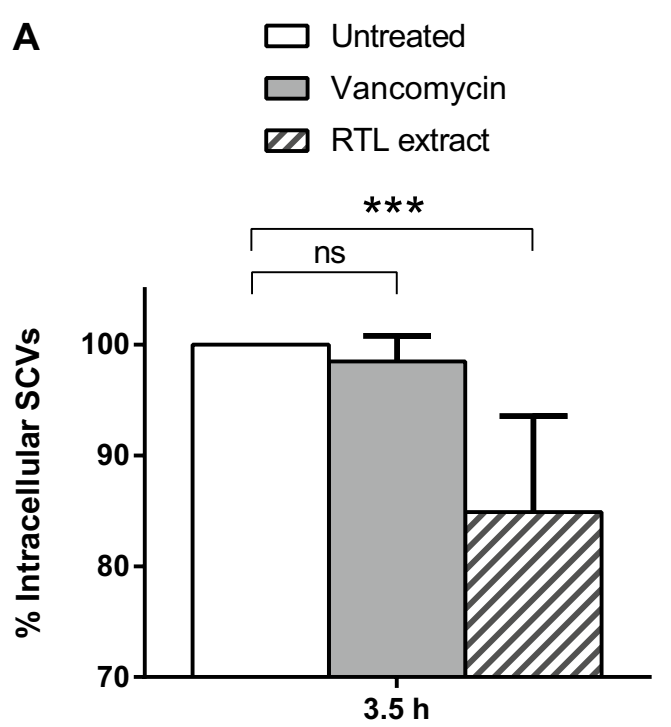

Incubation period
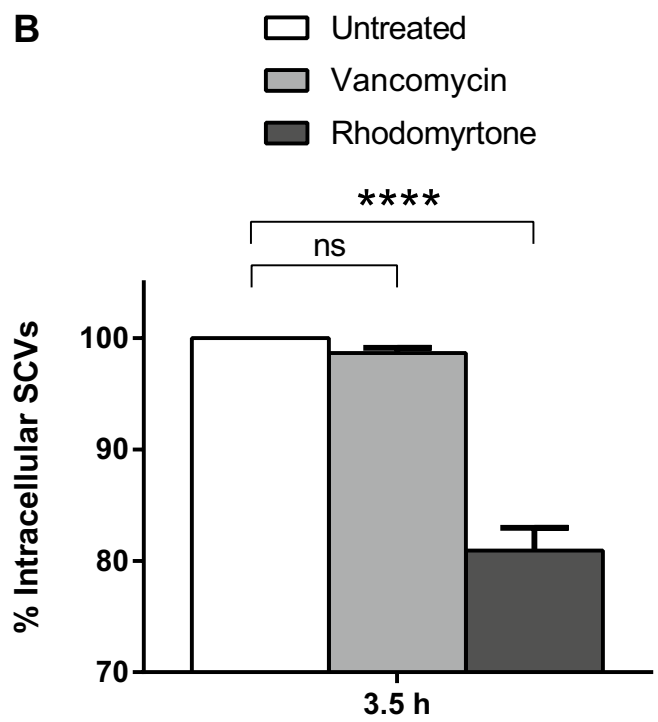

Incubation period

Figure 2 Effect of the Rhodomyrtus tomentosa leaves (RTL) extract (A) and rhodomyrtone (B) at half their minimal inhibitory concentrations (MICs) on the internalization of the small-colony variant (SCV) strain Newbould $\Delta$ hemB into MAC-T cells after a $3.5 \mathrm{~h}$ treatment. Vancomycin was also used as a control in each assay. The bars represent the means of three independent experiments with standard deviations. One-way analysis of variance was performed with Dunnett's post-test: ${ }^{* *} P=0.0002$; ${ }^{* * *} P=0.0001$; ns: not significant $(P>0.05)$.

control cells (Figures 2A and B). Noteworthy, none of the antibacterial agents used here at half their MICs reduced the amounts of viable bacteria in the cell culture medium for an incubation period of $3.5 \mathrm{~h}$ in the absence of MAC-T cells or in the CAMHB medium as seen in time-kill kinetic assays (Figures $1 \mathrm{~B}$ and $\mathrm{D}$ ). The decrease in SCV internalization by the RTL extract or rhodomyrtone can therefore not be due to bacterial killing prior to internalization into MAC-T cells.

\section{Benefits of compound combinations}

In a checkerboard assay, multiple dilutions of 10 different antibiotics were combined with increasing concentrations of the RTL extract or rhodomyrtone, and a FIC index was determined for each tested combination against $S$. aureus Newbould for detection of possible synergy between some antibiotics and the natural products. For most antibiotics, no synergy was recorded. The exceptions were pirlimycin and oxytetracycline, which when combined with half the MIC of the RTL extract, the MIC of the antibiotic dropped by 64 (oxytetracycline) to 128 (pirlimycin) times (Table 3). The resulting FIC index was $\sim 0.5(0.508-0.516)$, which technically depicts an additive effect at the limit of synergism $(\leq 0.5)$. Rhodomyrtone, which is already as potent as most of the antibiotics tested did not show any synergy against that $S$. aureus strain (FIC index of 1.01).

Since the RTL extract was bacteriostatic at half its MIC (Figures 1A and B), the bactericidal activity of the RTL extract in combination with a fraction of the pirlimycin MIC was evaluated to see if the additive effect or weak synergy observed in the checkerboard assay translated into killing. Figure 3 shows indeed that

Table 3 Minimal inhibitory concentrations (MICs, $\mu \mathrm{g} / \mathrm{mL}$ ) and the fractional inhibitory concentration index ( $\sum$ FIC) of the Rhodomyrtus tomentosa leaves extract (RTLex) in combination with antibiotics (ATB) against S. aureus strain Newbould

\begin{tabular}{lllll}
\hline Antibiotic & $\begin{array}{l}\text { Individual MIC } \\
\text { ATB/RTLex }\end{array}$ & $\begin{array}{l}\text { MIC in combination } \\
\text { ATB/RTLex }\end{array}$ & $\begin{array}{l}\text { MIC fold improvement }^{\mathbf{c}} \\
\text { ATB/RTLex }^{\mathbf{b}}\end{array}$ & $\begin{array}{l}\sum \text { FIC }^{\mathbf{d}} \\
\text { Pirlimycin }\end{array}$ \\
Oxytetracycline & $0.5 / 16$ & $0.004 / 8$ & $128 / 2$ & 0.508 \\
\hline
\end{tabular}

\footnotetext{
${ }^{a}$ MIC of the antibiotic (ATB) and MIC of the RTL extract (RTLex) when used alone.

${ }^{b}$ MIC of the ATB and MIC of the RTLex when used in combination.

c The fold improvement of the MIC is the ratio of the MIC alone/MIC in combination for the ATB or the RTLex.

${ }^{d} \mathrm{~A} \sum \mathrm{FIC}$ of $\leq 0.5$ is defined as synergism; $0.5-1$ as additive; $>1-4$ as indifference; $>4$ as antagonism.
} 


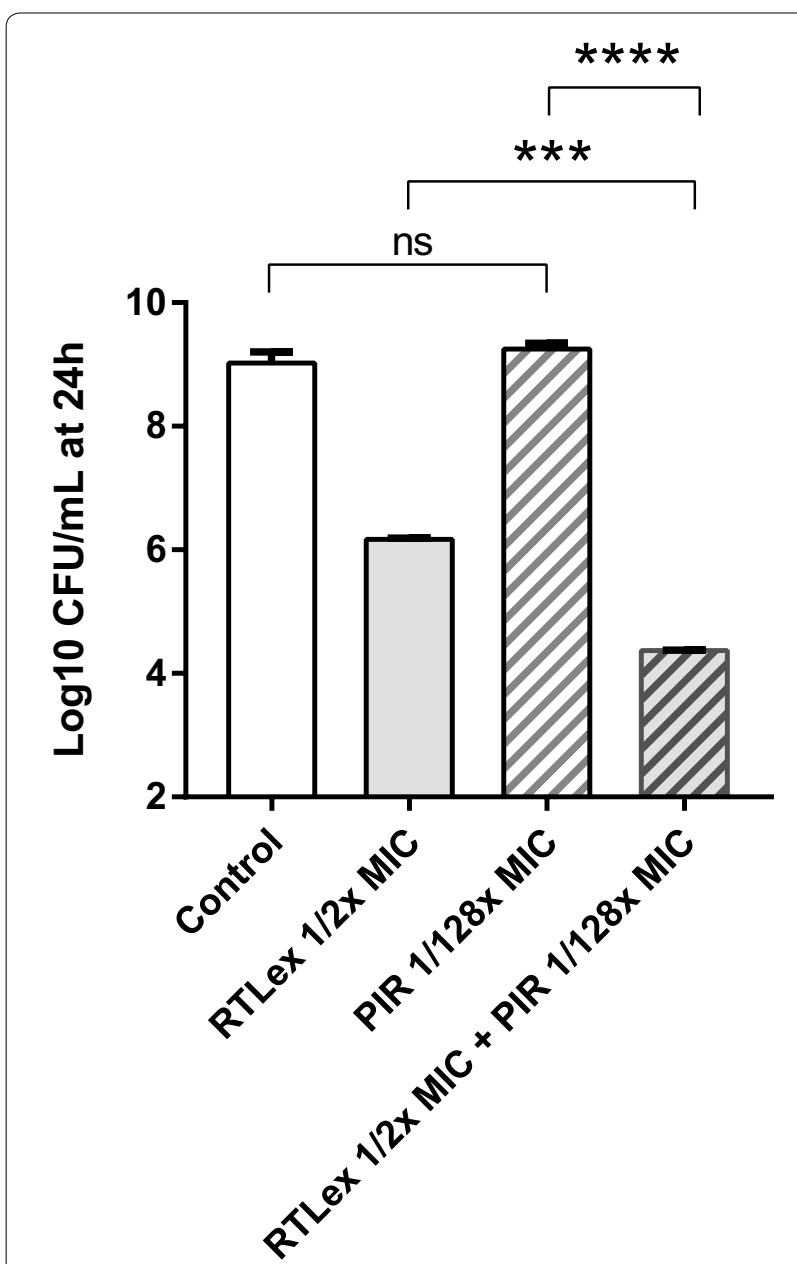

Figure 3 Bactericidal activity of sub-inhibitory concentrations of the Rhodomyrtus tomentosa leaves extract (RTLex) and pirlimycin (PIR) used alone or in combination against $S$. aureus Newbould after $\mathbf{2 4} \mathbf{h}$. The bars represent the means of three independent experiments with standard deviations. Two-way ANOVA and Tukey's multiple comparisons test: ${ }^{* * *} P<0.0001 ;{ }^{* * *} P=0.0002$; ns: not statistically significant $(P>0.05)$.

the combination of half the MIC of the RTL extract with $1 / 128$ the MIC of pirlimycin kills significantly more than either of these agents used alone $(P=0.0002$ and $P<0.0001$, respectively). These results show that the RTL extract could be employed to drastically reduce the useful concentration of an antibiotic like pirlimycin.

\section{Efficacy of the RTL extract alone or in combination with pirlimycin in vivo}

In vivo experiments were carried out to determine the therapeutic effects of the RTL extract, pirlimycin and a combination of both against a $S$. aureus challenge in the mouse mastitis model. The biofilm hyperproducing strain S. aureus 2117 was used for the challenge. The number of bacterial cells inside the mammary glands

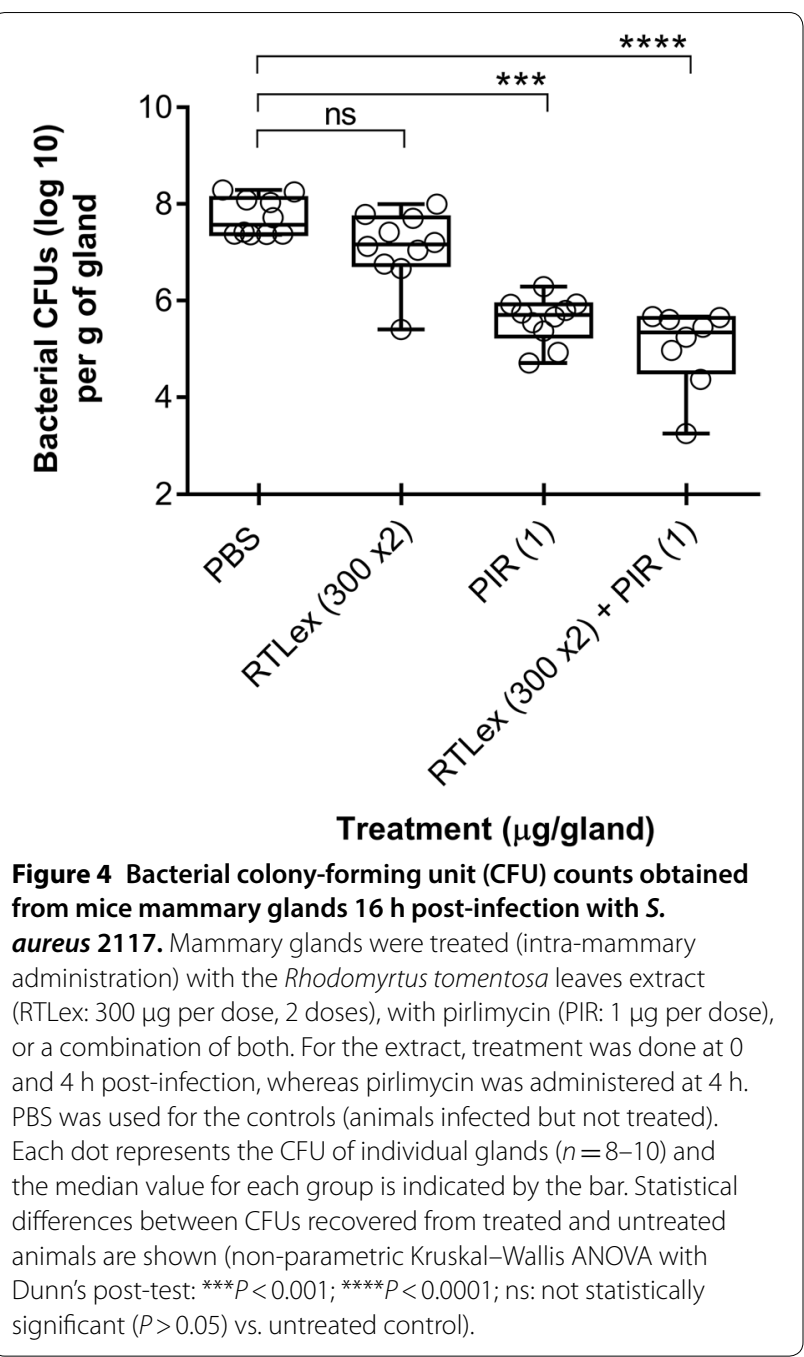

in the control condition (PBS treatment) reached a maximum of approximately $1 \times 10^{8} \mathrm{CFU} /$ gland after $16 \mathrm{~h}$ (Figure 4). The administration of the extract that was done twice $(2 \times 300 \mu \mathrm{g} /$ gland $)$ at $0 \mathrm{~h}$ and $4 \mathrm{~h}$ postinfection did not significantly reduce the bacterial load when compared to the untreated control, although the bacterial counts in many of the treated glands showed lower CFU counts. On the other hand, the number of bacteria was significantly reduced $(P<0.001)$ to approximately $10^{6} \mathrm{CFU} /$ gland by a treatment with pirlimycin $(1 \mu \mathrm{g} / \mathrm{gland}$ at $4 \mathrm{~h}$ post-infection). Interestingly, there was an additional significant antibacterial effect when pirlimycin was used in combination with the RTL extract $(P<0.0001)$ when compared to the PBS control group. However, in those experimental conditions, there was no significant difference between treatment with pirlimycin alone or when in combination with the extract, although the bacterial counts in some of the glands treated with the combination reached the lowest 
CFU counts (Figure 4). Almost identical results were obtained when mice were challenged with strain Newbould (data not shown).

These results show that the RTL extract used at such a concentration and without any specific pharmacological formulation has some but limited activity in this mouse mastitis model. To that effect, we have determined the MIC of the RTL extract and of other antibiotics in the presence of $5 \%$ casein to mimic the milk environment. The results demonstrated that the addition of casein raised the MIC and MBC of the RTL extract since a fourfold loss of the activity was observed (data not shown). On the other hand, pirlimycin showed no reduction of the activity in presence of casein.

\section{Discussion}

Considering that intramammary infections (IMIs) are responsible for most of the antibiotic use in dairy farms and that bacterial resistance to traditional antibiotics continues to progress and spread, the growing consumer concerns about food-related health risks have prompted the search for antibiotic alternatives for prevention and treatment of bovine mastitis. Since many medicinal plants have traditionally been used for remedy of some infectious diseases, plant extracts represent interesting sources of novel antibacterial substances.

In the present study, we are reporting the antibacterial effects of an ethanolic extract of $R$. tomentosa leaves (RTL), a Thai traditional herbal plant, and of rhodomyrtone, a compound purified from this plant, against staphylococcal strains associated with bovine mastitis. The RTL extract and purified rhodomyrtone provided a strong antibacterial activity against staphylococci strains with MICs of 8-16 and $0.25-0.5 \mu \mathrm{g} / \mathrm{mL}$, respectively, including against $S$. aureus SCV and MRSA strains. The MICs obtained in the present study can be advantageously compared the other purified compounds from plant products or plant-derived antimicrobials. For instance, salvipisone, a diterpenoid compound isolated from the hairy roots of Salvia sclarea, has previously shown antibacterial activity against S. aureus and S. epidermidis with MIC values ranging from 9.37 to $18.75 \mu \mathrm{g} /$ $\mathrm{mL}$ [26], whereas berberine, isolated from Coptidis rhizome, exhibited a bacteriostatic effect on S. epidermidis strains with MICs of 64 to $256 \mu \mathrm{g} / \mathrm{mL}$ [27]. Another example is thymoquinone, an active principle found in Nigella sativa seeds, which showed MICs against Grampositive cocci (including $S$. aureus and S. epidermidis) ranging from 8 to $32 \mu \mathrm{g} / \mathrm{mL}$ [28].

Together with the growth inhibitory effect, other properties may be required from antibacterial substances in order to control pathogens like S. aureus, which possesses multiple strategies to colonize and persists in the bovine mammary gland. Here, we have also observed that the RTL extract and rhodomyrtone reduce internalization of $S$. aureus into bovine epithelial mammary cells, and that the RTL extract can improve the activity of some traditional antibiotics. While the mechanisms underlying such observations are yet to be identified, it is known that the RTL extract can affect the staphylococcal cells by increasing cell surface hydrophobicity in a concentration dependent manner [19]. Also, other pharmacological activities of the RTL extract and rhodomyrtone have been evaluated and documented in previous studies. For instances, the plant extract displayed a strong antibiofilm forming effect against staphylococci [29], an antiquorum sensing activity against Streptococcus pyogenes [30], as well as anti-oxidative [31] and anti-inflammatory properties [32]. Moreover, rhodomyrtone can enhance the killing activities of human monocytes and induce the expression of local host immunity during $S$. aureus infections [33]. All of these RTL extract or rhodomyrtone properties may thus act synergistically to combat $S$. aureus infections.

The ease of production of the RTL extract compared to the steps required for the purification of rhodomyrtone was a major motivation for the realization of this study. Both, the extract and pure compound, have a similar antibacterial profile in terms of $\mathrm{MIC} / \mathrm{MBC}$ ratios and spectrum of activity, in accordance to the fact that the RTL extract contains a diluted amount of rhodomyrtone. However, some interesting differences were observed as no synergy with antibiotics was found with pure rhodomyrtone. Also, the toxicity of the pure compound toward mammalian cells suddenly increased at a certain concentration threshold but, for the extract, a more linear doseresponse effect was observed. While rhodomyrtone represents at least one of the bioactive compounds, the RTL extract likely contains other bioactive compounds which may contribute to the various antibacterial, antioxidant and anti-inflammatory effects reported for the extract.

Experiments were carried out to determine the therapeutic effects of the RTL extract on S. aureus in a mouse mastitis model of infection. As sometimes seen with other natural products or extracts, the RTL extract was not as effective as expected in vivo and will likely need to be formulated to demonstrate its full antibacterial activity in a complex environment like the mammary gland. Many factors could have accounted for the low in vivo efficacy, but we found that the presence of milk casein might be sufficient to reduce the antibacterial effect of the RTL extract, and this possibly through casein binding to active RTL components.

In summary, the extract and the pure compound could reduce the ability of $S$. aureus SCVs to invade and 
survive intracellularly as shown by the reduced number of bacteria found inside bovine mammary epithelial cells after treatment. Moreover, a sub-MIC of the extract demonstrated an improved bactericidal activity when in combination with a sub-MIC of pirlimycin against $S$. aureus in vitro. While a proper pharmacological formulation would seem to be required to reveal the full activity of the RTL extract in vivo, our work show promising results that could qualify the extract as a possible natural alternative to traditional antibiotics or at the least as an agent that could help reduce antibiotic use in dairy farms. This view is in agreement with the conclusions of the $2^{\text {nd }}$ International Symposium on Alternatives to Antibiotics, which were recently reviewed by Lillehoj et al. [34] and which highlight the potential role and importance of phytochemicals in the global efforts aimed at reducing antibiotic use in animal productions.

\begin{abstract}
Abbreviations
ATB: antibiotic; BSA: bovine serum albumin; CFU: colony forming unit; CNS: coagulase negative staphylococci; DMEM: Dulbecco's Modified Eagle's Medium; DMSO: dimethyl sulfoxide; D-PBS: Dulbecco's phosphate-buffered saline; FBS: fetal bovine serum; FIC: fractional inhibitory concentration; IMI: intramammary infection; LDH: lactate dehydrogenase; MBCs: minimum bactericidal concentrations; MHA: Mueller-Hinton agar; MHBCA: cation-adjusted Mueller-Hinton broth; MIC: minimal inhibitory concentration; MOI: multiplicity of infection; MRSA: methicillin-resistant Staphylococcus aureus; MSA: mannitol salt agar; OD: optical density; PBS: phosphate buffered saline; PIR: pirlimycin; RTL/RTLex: Rhodomyrtus tomentosa ethanolic leaf extract; SCV: small colony variant; TSA: tryptic soy agar; TSB: tryptic soy broth; FIC: fractional inhibitory concentration index.
\end{abstract}

\section{Acknowledgements}

Authors thank Dr. Brian Hodgson (deceased) for assistance with the English.

\section{Authors' contributions}

AM and EB completed the experimental works. FM and SV provided expertise and supervised throughout the process. All the authors reviewed the manuscript and contributed to the scientific content of this paper. All authors read and approved the final manuscript.

\section{Funding}

This work was supported by Research and Researcher for Industries, Ph.D. program (Grant No. PHD 56l0006) and TRF Senior Research Scholar (Grant No. RTA6180006), the Thailand Research Fund. This research was also funded by the Natural Sciences and Engineering Research Council of Canada (NSERC Grant No. 2015-05916 to F. Malouin).

\section{Availability of data and materials}

The datasets used and/or analyzed during the current study are available from the corresponding author on reasonable request.

\section{Ethics approval and consent to participate}

All the experiments performed with mice were approved by the ethics committees on animal experimentation of the Faculté des sciences of the Université de Sherbrooke, and were conducted in accordance with the guidelines of the Canadian Council on Animal Care (CCAC).

\section{Competing interests}

The authors declare that they have no competing interests.

\section{Author details}

${ }^{1}$ Department of Microbiology and Excellence Research Laboratory on Natural Products, Faculty of Science and Natural Product Research Center of Excellence, Prince of Songkla University, Hat Yai, Songkhla 90112, Thailand. ${ }^{2}$ Centre d'Étude et de Valorisation de la Diversité Microbienne (CEVDM), Département de biologie, Faculté des sciences, Université de Sherbrooke, Sherbrooke, QC J1K 2R1, Canada. ${ }^{3}$ School of Medicine, Walailak University, Tha Sala, Nakhon Si Thammarat 80160, Thailand.

Received: 21 March 2019 Accepted: 25 May 2019

Published online: 20 June 2019

\section{References}

1. Bergonier D, Sobral D, Feßler AT, Jacquet E, Gilbert FB, Schwarz S, Treilles M, Bouloc P, Pourcel C, Vergnaud G (2014) Staphylococcus aureus from 152 cases of bovine, ovine and caprine mastitis investigated by multiplelocus variable number of tandem repeat analysis (MLVA). Vet Res 45:97

2. Reyher KK, Dufour S, Barkema HW, Des Côteaux L, DeVries TJ, Dohoo IR, Keefe GP, Roy JP, Scholl DT (2011) The National Cohort of Dairy Farms-a data collection platform for mastitis research in Canada. J Dairy Sci 94:1616-1626

3. Pichette-Jolette S, Millette G, Demontier E, Bran-Barrera D, Cyrenne M, Ster C, Haine D, Keefe G, Malouin F, Roy J-P (2019) Partial prediction of the duration and the clinical status of Staphylococcus aureus bovine intramammary infections based on the phenotypic and genotypic analysis of isolates. Vet Microbiol 228:188-195

4. Foster TJ, Geoghegan JA, Ganesh VK, Höök M (2014) Adhesion, invasion and evasion: the many functions of the surface proteins of Staphylococcus aureus. Nat Rev Microbiol 12:49-62

5. Flannagan RS, Heit B, Heinrichs DE (2015) Intracellular replication of Staphylococcus aureus in mature phagolysosomes in macrophages precedes host cell death, and bacterial escape and dissemination. Cell Microbiol 18:514-535

6. Brouillette E, Martinez A, Boyll BJ, Allen NE, Malouin F (2006) Persistence of a Staphylococcus aureus small-colony variant under antibiotic pressure in vivo. FEMS Immunol Med Microbiol 41:35-41

7. Moisan H, Brouillette E, Jacob CL, Langlois-Bégin P, Michaud S, Malouin F (2006) Transcription of virulence factors in Staphylococcus aureus smallcolony variants isolated from cystic fibrosis patients is influenced by SigB. J Bacteriol 188:64-76

8. Johns BE, Purdy KJ, Tucker NP, Maddocks SE (2015) Phenotypic and genotypic characteristics of small colony variants and their role in chronic infection. Microbiol Insights 8:15-23

9. Löffler B, Tuchscherr L, Niemann S, Peters G (2014) Staphylococcus aureus persistence in non-professional phagocytes. Int J Med Microbiol 304:170-176

10. Tuchscherr L, Löffler B (2016) Staphylococcus aureus dynamically adapts global regulators and virulence factor expression in the course from acute to chronic infection. Curr Genet 62:15-17

11. Tuchscherr L, Medina E, Hussain M, Völker W, Heitmann V, Niemann S, Holzinger D, Roth J, Proctor RA, Becker K, Peters G, Löffler B (2011) Staphylococcus aureus phenotype switching: an effective bacterial strategy to escape host immune response and establish a chronic infection. EMBO Mol Med 3:129-141

12. Proctor RA, von Eiff C, Kahl BC, Becker K, McNamara P, Herrmann M, Peters G (2006) Small colony variants: a pathogenic form of bacteria that facilitates persistent and recurrent infections. Nat Rev Microbiol 4:295

13. Mitchell G, Brouillette E, Séguin DL, Asselin A-E, Jacob CL, Malouin F (2010) A role for sigma factor B in the emergence of Staphylococcus aureus small-colony variants and elevated biofilm production resulting from an exposure to aminoglycosides. Microb Pathog 48:18-27

14. Atalla H, Gyles C, Jacob CL, Moisan H, Malouin F, Mallard B (2008) Characterization of a Staphylococcus aureus small colony variant (SCV) associated with persistent bovine mastitis. Foodborne Pathog Dis 5:785-799

15. García-Álvarez L, Holden MTG, Lindsay H, Webb CR, Brown DFJ, Curran MD, Walpole E, Brooks K, Pickard DJ, Teale C, Parkhill J, Bentley SD, Edwards GF, Girvan EK, Kearns AM, Pichon B, Hill RLR, Larsen AR, Skov RL, Peacock SJ, Maskell DJ, Holmes MA (2011) Meticillin-resistant Staphylococcus aureus with a novel mecA homologue in human and bovine 
populations in the UK and Denmark: a descriptive study. Lancet Infect Dis 11:595-603

16. Voravuthikunchai SP, Limsuwan S, Chusri S (2007) New perspectives on herbal medicines for bacterial infection: natural products II. Studium Press LLC, Houston

17. Mordmuang A, Voravuthikunchai SP (2015) Rhodomyrtus tomentosa (Aiton) Hassk. leaf extract: an alternative approach for the treatment of staphylococcal bovine mastitis. Res Vet Sci 102:242-246

18. Saising J, Hiranrat A, Mahabusarakam W, Ongsakul M, Voravuthikunchai SP (2008) Rhodomyrtone from Rhodomyrtus tomentosa (Aiton) Hassk. as a natural antibiotic for staphylococcal cutaneous infections. J Health Sci 54:589-595

19. Mordmuang A, Shankar S, Chethanond U, Voravuthikunchai SP (2015) Effects of Rhodomyrtus tomentosa leaf extract on staphylococcal adhesion and invasion in bovine udder epidermal tissue model. Nutrients 7:8503-8517

20. Diarra MS, Petitclerc D, Lacasse P (2002) Response of Staphylococcus aureus isolates from bovine mastitis to exogenous iron sources. J Dairy Sci 85:2141-2148

21. Veh KA, Klein RC, Ster C, Keefe G, Lacasse P, Scholl D, Roy JP, Haine D, Dufour S, Talbot BG, Ribon AOB, Malouin F (2015) Genotypic and phenotypic characterization of Staphylococcus aureus causing persistent and nonpersistent subclinical bovine intramammary infections during lactation or the dry period. J Dairy Sci 98:155-168

22. Hiranrat A, Mahabusarakam W (2008) New acylphloroglucinols from the leaves of Rhodomyrtus tomentosa. Tetrahedron 64:11193-11197

23. Clinical and Laboratory Standards Institute (2015) Methods for dilution antimicrobial susceptibility tests for bacteria that grow aerobically; CLSI approved standard M07-A10, 10th edn. CLSI, Wayne

24. Doern CD (2014) When does 2 plus 2 equal 5 ? A review of antimicrobial synergy testing. J Clin Microbiol 52:4124-4128

25. Diarra MS, Block G, Rempel H, Oomah BD, Harrison J, McCallum J, Boulanger S, Brouillette É, Gattuso M, Malouin F (2013) In vitro and in vivo antibacterial activities of cranberry press cake extracts alone or in combination with $\beta$-lactams against Staphylococcus aureus. BMC Complement Altern Med 13:90

26. Kuźma Ł, Różalski M, Walencka E, Różalska B, Wysokińska H (2007) Antimicrobial activity of diterpenoids from hairy roots of Salvia sclarea
L.: salvipisone as a potential anti-biofilm agent active against antibiotic resistant staphylococci. Phytomedicine 14:31-35

27. Wang X, Yao X, Za Zhu, Tang T, Dai K, Sadovskaya I, Flahaut S, Jabbouri S (2009) Effect of berberine on Staphylococcus epidermidis biofilm formation. Int J Antimicrob Agents 34:60-66

28. Chaieb K, Kouidhi B, Jrah H, Mahdouani K, Bakhrouf A (2011) Antibacterial activity of thymoquinone, an active principle of Nigella sativa and its potency to prevent bacterial biofilm formation. BMC Complement Altern Med 11:29

29. Saising J, Ongsakul M, Voravuthikunchai SP (2011) Rhodomyrtus tomentosa (Aiton) Hassk. ethanol extract and rhodomyrtone: a potential strategy for the treatment of biofilm-forming staphylococci. J Med Microbiol 60:1793-1800

30. Limsuwan S, Voravuthikunchai SP (2008) Boesenbergia pandurata (Roxb.) Schltr., Eleutherine americana Merr. and Rhodomyrtus tomentosa (Aiton) Hassk. as antibiofilm producing and antiquorum sensing in Streptococcus pyogenes. FEMS Immunol Med Microbiol 53:429-436

31. Goodla L, Voravuthikunchai S, Hutadilok-Towatana N (2012) Acetone extract from Rhodomyrtus tomentosa: a potent natural antioxidant. Evid Based Complement Altern Med 2012:1-8

32. Jeong D, Yang WS, Yang Y, Nam G, Kim JH, Yoon DH, Noh HJ, Lee S, Kim TW, Sung G-H, Cho JY (2013) In vitro and in vivo anti-inflammatory effect of Rhodomyrtus tomentosa methanol extract. J Ethnopharmacol 146:205-213

33. Srisuwan S, Tongtawe P, Srimanote P, Voravuthikunchai SP (2014) Rhodomyrtone modulates innate immune responses of THP-1 monocytes to assist in clearing methicillin-resistant Staphylococcus aureus. PLoS One 9:e110321

34. Lillehoj H, Liu Y, Calsamiglia S, Fernandez-Miyakawa ME, Chi F, Cravens RL, Oh S, Gay CG (2018) Phytochemicals as antibiotic alternatives to promote growth and enhance host health. Vet Res 49:76

\section{Publisher's Note}

Springer Nature remains neutral with regard to jurisdictional claims in published maps and institutional affiliations.
Ready to submit your research? Choose BMC and benefit from:

- fast, convenient online submission

- thorough peer review by experienced researchers in your field

- rapid publication on acceptance

- support for research data, including large and complex data types

- gold Open Access which fosters wider collaboration and increased citations

- maximum visibility for your research: over $100 \mathrm{M}$ website views per year

At $\mathrm{BMC}$, research is always in progress.

Learn more biomedcentral.com/submissions 